\title{
Neural mechanisms underlying word- and phrase-level morphological parsing
}

\section{Leminen, Alina}

2016-05

Leminen , A , Jakonen , S , Leminen , M , Mäkelä , J P \& Lehtonen , M 2016 , ' Neural mechanisms underlying word- and phrase-level morphological parsing ' , Journal of Neurolinguistics , vol. 38 , pp. 26-41 . https://doi.org/10.1016/j.jneuroling.2015.10.003

http://hdl.handle.net/10138/223819

https://doi.org/10.1016/j.jneuroling.2015.10.003

publishedVersion

Downloaded from Helda, University of Helsinki institutional repository.

This is an electronic reprint of the original article.

This reprint may differ from the original in pagination and typographic detail.

Please cite the original version. 
Research paper

\title{
Neural mechanisms underlying word- and phrase-level morphological parsing
}

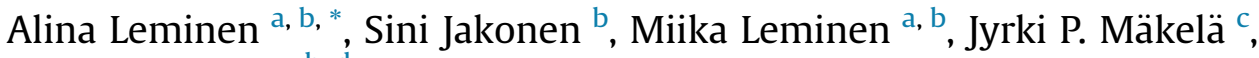 \\ Minna Lehtonen ${ }^{\mathrm{b}, \mathrm{d}}$ \\ a Center of Functionally Integrative Neuroscience, Department of Clinical Medicine, Aarhus University, 8000, Aarhus, Denmark \\ ${ }^{\mathrm{b}}$ Cognitive Brain Research Unit, Cognitive Science, Institute of Behavioural Sciences, University of Helsinki, 00014, Helsinki, Finland \\ ${ }^{\mathrm{c}}$ BioMag Laboratory, HUSLAB, Hospital District of Helsinki and Uusimaa, 00029, Helsinki, Finland \\ d Department of Psychology, Abo Akademi University, 20500, Turku, Finland
}

\section{A R T I C L E I N F O}

\section{Article history:}

Received 27 March 2015

Received in revised form 19 October 2015

Accepted 23 October 2015

Available online 9 November 2015

\section{Keywords:}

Morphosyntax

Morphology

Inflection

N400

LAN

P600

\begin{abstract}
A B S T R A C T
How is morphological and morphosyntactic information processed during sentence reading? Are the neural mechanisms underlying word- and phrase-level combinatorial processing overlapping or distinct? Here, electroencephalography (EEG) and magnetoencephalography (MEG) responses were recorded simultaneously during silent reading of Finnish sentences. The experimental conditions included 1) well-formed grammatical sentences (correct condition), 2) sentences containing morphosyntactic violations (adjective-noun number agreement violations), 3) morphological violations (incorrect stem allomorph and inflectional suffix combination), and 4) combined violations, containing both morphosyntactic and morphological violations. Signal space and source modeling results showed that morphosyntactic violations elicited a left anterior negativity effect, generated particularly in the left inferior frontal area. Morphological violations elicited a widespread negativity, resembling the $\mathrm{N} 400$. The neural sources of this negativity were localized most prominently to the right temporal cortical networks. Furthermore, all violations elicited P600 effects with similar widespread bilateral fronto-temporal neural generators that did not differ between morphosyntactic and morphological conditions. Our findings suggest at least partially distinct subnetworks in the fronto-temporal cortices for morphological and morphosyntactic parsing during the earlier stages of processes ( $\sim 400 \mathrm{~ms}$ post stimulus onset) and shared neural generators for the later processing stages. (C) 2015 Elsevier Ltd. All rights reserved.
\end{abstract}

\section{Introduction}

Comprehension of a sentence requires understanding individual words, as well as accessing information encoded in the relations between words (i.e. syntactic structure). Sentences can be broken down into words and even further meaningful units, i.e. morphemes within words. Morphemes constitute a building block of natural languages by enabling production of complex words, such as regular plural nouns (boy $+s$ ) or verbs in past perfect simple form (walk + ed). However, languages differ in regard to the role that inflectional affixes versus word order play in assigning syntactic structure to sentences.

\footnotetext{
* Corresponding author. Center of Functionally Integrative Neuroscience/MINDLab, Department of Clinical Medicine, Aarhus University, 8000 Aarhus C, Denmark.

E-mail address: alina.leminen@cfin.au.dk (A. Leminen).
} 
The present study uses Finnish as its target language. Finnish is a Finno-Ugric agglutinative language with a complex inflectional system, where most grammatical relations are realized at morpheme level. This is reflected in the number of inflectional suffixes that are actively used; in Finnish, nouns can take up to 15 different inflectional cases. Finnish is also a language susceptible to morphophonological changes, such as consonant gradation, ${ }^{1}$ and thus correct inflection of words often involves attaching an inflectional suffix to a correct stem allomorph (e.g., lauta 'a board', lauta + an 'to a board', lauda + lla 'on a board'). Each noun can have up to 140 possible inflectional forms (clitics excluded), making Finnish a particularly interesting language to investigate complex combinatorial processing. At the phrasal level, adjacent elements must follow the same inflectional form. For instance, not only subject and verb must agree e.g. in number, but also a preceding adjective must agree with the noun in both number and case (e.g., Surffaaja osti uuden $_{\text {GEN.SG }}$ laudan $_{\text {GEN.SG }}$ lomamatkaa varten. $_{\text {. }}$ 'The surfer bought a new board for a vacation trip'). To sum up, reaching the final inflectional form in Finnish sentences, as in many other languages, requires integrating morphological and morphosyntactic information.

Morphosyntactic agreement has been defined as the covariation of inflectional morphology between related words (Molinaro, Carreiras, \& Dunabeitia, 2012). Thus, it operates at the phrasal level, while morphological processing takes place at the word level, between morpheme boundaries. Processing of complex syntactic structures and regular inflectional structures typically activates left-fronto-temporal cortical networks (Bozic \& Marslen-Wilson, 2010; Marslen-Wilson \& Tyler, 2007). Parsing of inflected words is often assumed to involve both morphological parsing, which decomposes complex forms into stems and affixes, ${ }^{2}$ and grammatical processing elicited by the grammatical functions of inflectional affixes. ${ }^{3}$ Hence, an interesting question arises - are there spatiotemporal differences in brain activation between morphosyntactic and morphological parsing? Despite abundant research on the neural correlates of morphological and morphosyntactic processing, the exact relationship between the two - the time-course of phrase and word level processes and their possible interactions - have not yet been thoroughly investigated. Therefore, we asked here if the neural mechanisms of parsing sequences of morphemes (i.e. word-level agreement) are similar to those of parsing words connected in sequences and what the mechanisms behind these processes are.

Phrase and sentence level parsing have been extensively investigated using event-related potentials (ERP) and their magnetic counterparts (event-related fields, ERF), as ERP/ERFs allow parsing processes to be tracked with a time-scale of milliseconds. Studies of phrase- and sentence-level processing have, in many cases, reported the N400 component, the left anterior negativity (LAN), and the P600 (for a review, see e.g., Friederici \& Wartenburger, 2010; Friederici \& Weissenborn, 2007). The N400 has been typically observed during various lexical-semantic violations (for a review, see e.g., Federmeier, Segal, Lombrozo, \& Kutas, 2000; Kutas \& Federmeier, 2011) and its neural sources have been localized to the left and right superior temporal cortices (Helenius et al., 2002; Uusvuori, Parviainen, Inkinen, \& Salmelin, 2008; Vartiainen, Parviainen, \& Salmelin, 2009), the middle and anterior temporal areas, the inferior frontal areas (Halgren et al., 2002), and posterior frontal regions (Kielar, Panamsky, Links, \& Meltzer, 2014). The N400 presumably reflects lexical or semantic processes such as lexical access, initial access to long-term semantic memory, a dynamic process of meaning construction (Kutas \& Federmeier, 2000, 2011; Lau, Almeida, Hines, \& Poeppel, 2009; Lau, Phillips, \& Poeppel, 2008), as well as semantic integration or unification (Hagoort, Baggio, \& Willems, 2009). Phrase-level morphosyntactic violations have typically elicited the left anterior negativity (LAN) (Friederici, 2002; Friederici \& Kotz, 2003; Friederici \& Weissenborn, 2007; Rossi, Gugler, Hahne, \& Friederici, 2005) and P600 effects (Friederici \& Wartenburger, 2010; Friederici \& Weissenborn, 2007), although P600 effects have also been observed in semantic (Kuperberg, 2007) and morphological (derivational, i.e. word formation) processes (Leinonen, Brattico, Järvenpää, \& Krause, 2008). The P600 has been proposed to reflect repair, reanalysis, or continued combinatorial processes of complex or violated linguistic stimuli (Friederici \& Weissenborn, 2007; Kuperberg, 2007), where lexicalsemantic and syntactic information is assumed to interact (Friederici \& Weissenborn, 2007). With MEG, the sources of LAN have been localized to the left superior temporal cortex (Leminen et al., 2011; Service, Helenius, Maury, \& Salmelin, 2007). The sources of the P600 have been localized to bilateral posterior superior temporal cortices (Grodzinsky \& Friederici, 2006; Service et al., 2007) and to bilateral frontal, posterior temporal, and parietal regions (Kielar et al., 2014). With particular importance to our study, agreement violations (e.g., The old waiter *serve with inattentive expression/The old waiter serves with inattentive expression) have frequently elicited the LAN effect (typically together with the P600) (Angrilli et al., 2002; Molinaro, Barber, \& Carreiras, 2011; Palolahti, Leino, Jokela, Kopra, \& Paavilainen, 2005; Roehm, Bornkessel, Haider, \& Schlesewsky, 2005). For instance, number agreement in case inflection (Leinonen et al., 2008), person and number agreement violations (Linares, Rodriguez-Fornells, \& Clahsen, 2006), and clause-level past tense violations (Yesterday I *frown) (Newman, Ullman, Pancheva, Waligura, \& Neville, 2007) have all yielded anterior negativities. The LAN in agreement violations has been suggested to reflect a violation of expectancy (elicited by e.g., a subject noun phrase) for the target functional morphology (e.g., the following verb) (Molinaro et al., 2011). If the inflectional morphology of the target constituent does not match with the value expressed in the trigger constituent, then a LAN is observed (Molinaro et al., 2011; see

\footnotetext{
1 Consonant gradation is a type of consonant mutation, in which consonants alternate between various "grades", for example the word kukka 'flower' undergoes consonant gradation, when inflected to genitive case: kukka $>$ kuka $+\mathrm{n}$.

2 Our basic assumption here was that most Finnish inflected words are decomposed into stem and suffix during recognition. This assumption is based on extensive research on recognition of recognition of Finnish inflected words (see, e.g., Lehtonen \& Laine, 2003; Niemi et al., 1994; Soveri, Lehtonen, \& Laine, 2007).

3 Note that there are also accounts which do not assume that inflected words are processed via decomposition into morphological constituents (see, e.g., Baayen, Milin, Durdevic, Hendrix, \& Marelli, 2011; Gonnerman, Seidenberg, \& Andersen, 2007).
} 
also Bornkessel \& Schlesewsky, 2006). It should be noted that violations to other agreement requirements, such as grammatical case violation (The plane took *we to paradise and back) have tended to elicit the N400 (Gunter, Stowe, \& Mulder, 1997; Roehm et al., 2005) instead of the LAN. Some authors have observed a bilateral (Hagoort, 2003; Leinonen et al., 2008) or more widespread distribution of a LAN-like effect (e.g., Barber \& Carreiras, 2005; Münte, Matzke, \& Johannes, 1997). It has been suggested that morphosyntactic violation may rather elicit the N400 than the LAN when it requires lexical access, semantic reference, and/or discourse processing (Deutsch \& Bentin, 2001; Mancini, Molinaro, Rizzi, \& Carreiras, 2011; Molinaro, Vespignani, \& Job, 2008). The LAN can extend to more central and posterior areas (see e.g., Barber \& Carreiras, 2003), depending on the amount of non-syntactic information needed to process the violation, i.e., if access to lexical representations is required to resolve agreement mismatch, an additional N400 is elicited (Molinaro et al., 2011). A recent study has also proposed that the LAN might actually be a variant of the N400 (Tanner \& Van Hell, 2014).

Outside EEG and MEG studies, functional magnetic resonance imaging (fMRI) studies have shown that violations of morphosyntactic subject-verb agreement have elicited an enhanced activation in the inferior frontal gyrus (Kovelman, Baker, \& Petitto, 2008; Newman, Just, Keller, Roth, \& Carpenter, 2003; Ni et al., 2000). A transcranial magnetic stimulation (TMS) study has further shown a causal involvement of Broca's area (inferior frontal gyrus) in morphosyntactic processing (Carreiras, Pattamadilok, Meseguer, Barber, \& Devlin, 2012).

At the word level, inflectional violations such as goed (as opposed to the correct went), in which the -ed rule is incorrectly applied, have often yielded a larger left anterior negativity (LAN) than correct forms (Penke et al., 1997; Weyerts, Penke, Dohrn, Clahsen, \& Münte, 1997), similarly to those elicited by phrase-level morphosyntactic violations. In contrast, the LAN has typically not occurred for irregularized regular inflections (e.g., * bept as opposed to correct beeped), which have instead elicited more N400-like effects (Gross, Say, Kleingers, Clahsen, \& Münte, 1998; Morris \& Holcomb, 2005; Penke et al., 1997). Morphology-related LAN activity has been interpreted as reflecting more general combinatorial processing related to morphological structure building (Rodríguez-Fornells, Clahsen, Lleó, Zaake, \& Münte, 2001) as well as rule-governed compositional parsing of complex forms (Newman et al., 2007). In general, these response patterns have been interpreted to support the assumptions that the processing of regular inflection is combinatorial, whereas the processing of irregular inflection involves activation of a full-form representation (Clahsen, 1999; Pinker, 1991; Pinker \& Ullman, 2002; but see Stockall \& Marantz, 2006). fMRI and positron emission tomography (PET) studies on the processing of inflected words have shown that the left inferior frontal gyrus (LIFG) is involved in the processing of (regular) inflection (Tyler, Stamatakis, Post, Randall, \& Marslen-Wilson, 2005; Vannest, Polk, \& Lewis, 2005). In Finnish, greater activation of LIFG was found for inflected words than for monomorphemic words (Laine, Rinne, Krause, Teräs, \& Sipilä, 1999; Lehtonen et al., 2009; Lehtonen, Vorobyev, Hugdahl, Tuokkola, \& Laine, 2006). In addition to LIFG, superior temporal gyrus, and the anterior cingulate have been observed during the processing of inflected words (Bozic \& Marslen-Wilson, 2010; Lehtonen et al., 2009; Lehtonen et al., 2006; Tyler et al., 2005). MEG studies have reported that visually presented inflected nouns elicit stronger activation in the superior temporal areas than monomorphemic words (Vartiainen, Aggujaro, et al., 2009). Tyler et al. (2005) have suggested that the LIFG is involved in the segmenting of complex words into stems and affixes, whereas the superior temporal cortex is responsible for lexical access of the stem.

There are few existing ERP or MEG studies speaking directly to the issue of word-vs. sentence-level processing within the same study. Morris and Holcomb (2005) investigated if presenting a complex word in a sentence vs. as an isolated word in a list affects the ERP responses elicited by their recognition. They found LAN and P600 effects in response to morphological violations in sentences but no LAN for violations in single word presentation, only the P600. Morris and Holcomb (2005) also point out that LAN effects for morphological violations have in previous studies mostly been found when words have been embedded in sentence contexts (but see Penke et al., 1997). They conclude that LAN is likely to reflect difficulties at the morphosyntactic rather than morphological level. Steinhauer and Ullman (2002) used ERPs to investigate whether effects of morphophonology and morphosyntax occur in different time intervals. They utilized violated regular and irregular past tense forms (e.g., "Yesterday I * sail/*eat") and their correct forms and found that the morphophonological differences between word types elicited early (at 300-400 ms) LAN or N400-like responses, whereas morphosyntactic effects were reflected in a later time-window, in subsequent LAN (400-500 ms), in addition to a P600 effect.

In the present study, we used both EEG and MEG to identify the neural mechanisms relevant for the processing of phrasallevel and word-level parsing. A combination of EEG and MEG offered us a powerful means in drawing a comprehensive spatiotemporal map of the neural mechanisms of morphological and morphosyntactic processing. Since inflections are rarely presented in isolation, but are often embedded in sentences, we designed experimental conditions that allowed us to elucidate the temporal and spatial steps of parsing at different levels, within a sentence context. Our approach was to manipulate stimuli at phrasal and word levels and examine whether the neural mechanisms underlying language combinatorics are similar across the different parsing levels.

The phrasal level processing was examined by presenting violations of adjacent adjective-noun number agreement in

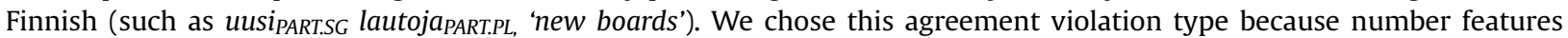
represent morphological cues to signal structural relations within a sentence (Molinaro et al., 2011). As number agreement violations have, in several cases, elicited the LAN-P600 pattern (Leinonen et al., 2008; Molinaro et al., 2011), we expected to observe a similar pattern in this condition as well. Based on the previous findings on phrase-level morphosyntax, these violations were expected to activate left lateralized fronto-temporal sources.

In the word-level morphological violation condition, we presented the participants with violations of stem + suffix combinations. We illegally combined an existing stem with an existing inflectional suffix, resulting in an incorrect stem 
allomorph and suffix combination (e.g., "lauta + ita 'board + plural partitive', correct form 'lauto + ja', where a different stem allomorph would be needed). This violation type leaves all morphosyntactic markings intact and any emerging processing differing between well-formed and ill-formed morphological constructions could serve as evidence in favor of distinct processes between word and phrasal level. In Finnish there is no explicit regular vs. irregular inflection distinction but rather a complex grammatically based morphophonological stem + suffix combination rule system. In this sense, all inflections in our study are considered regular. So far, to the best of our knowledge, only one study in Finnish has used a similar type of stem + suffix mismatch as a means of investigating the recognition of inflected forms (Lehtonen et al., 2007). These violations comprised of words with an existing noun stem and an existing noun suffix, violating the morphological rules of the language (e.g., lauta $+n$; 'board' + genitive suffix, when the correct form is lauda $+\mathrm{n}$, with a different stem allomorph). The stimuli were presented visually in a lexical decision task (Lehtonen et al., 2007). When contrasted with real words, such violations elicited a left-preponderant negativity beginning at $\sim 450 \mathrm{~ms}$, which was present both at the frontal electrode F3 as well as more posterior locations, thus not being a clear LAN effect (Lehtonen et al., 2007). In our study, all stimuli were presented in a sentence context. We aimed to see whether the inclusion of context would lead to elicitation of a LAN effect for these violations, as previous studies on inflection have shown more robust LAN effects in sentence contexts (Morris \& Holcomb, 2005). Observing LAN (and the P600) for both morphosyntactic and morphological conditions would suggest that these two types of combinatorial processes recruit largely similar neural networks. However, it has been claimed that LAN responses in fact constitute a family of effects with possibly different underlying processes (Krott, Baayen, \& Hagoort, 2006). Modeling the neural sources of these effects observed as surface ERP responses would provide a further important window on the question of functional overlap between the morphosyntactic and morphological conditions. By utilizing simultaneous EEG and MEG recordings, we thus aimed to gain a deeper insight into the neural similarities and differences between word and sentence level combinatorial processes.

As a further means of studying the (in)dependence of neural mechanisms underlying phrasal and word-level processing, we included combined violations, where both morphosyntactic and morphological violations occurred simultaneously (e.g.,

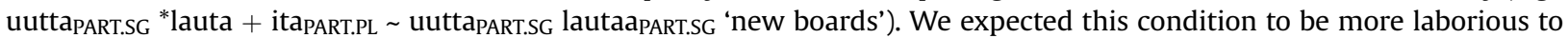
process, due to a double violation, and it could thus elicit enhanced anterior or posterior negativities (LAN or N400 effects) and later posterior positivities (P600), with fronto-temporal sources, when compared to the correct condition.

\section{Methods}

\subsection{Participants and ethical considerations}

Sixteen ( 3 male) healthy, right-handed native Finnish-speaking volunteers participated in the experiment. The mean age of the participants was 26 years (ranging from 18 to 27). The right-handedness of the participants was verified by a Finnish version of the Edinburgh Handedness Inventory (Oldfield, 1971). All participants were right-handed, had normal or correctedto-normal vision and none reported any hearing defects, linguistic dysfunctions or neurological disorders. The participants gave their written informed consent to participate in the experiments. The experiments were performed in accordance with the Declaration of Helsinki. Ethical permission for the experiment was issued by the Research Ethics Committee of the Helsinki and Uusimaa Hospital District.

\subsection{Stimuli}

The critical words consisted of 300 inflected Finnish nouns, embedded in simple declarative sentences. Half of the critical words were presented in genitive case, the other half in partitive case. These cases are assumed to be syntactic cases of Finnish (Kiparsky, 2001). A computerized search program WordMill (Laine and Virtanen, 1999) was used to obtain the lemma and bigram frequencies of the critical words from the unpublished Turun Sanomat lexical database with 22.7 million word tokens. Average lemma frequency was $106(S D=260)$ and bigram frequency $56.1(S D=19.2)$ per million. The average length of the critical words was $7(\mathrm{SD}=1)$ letters.

For every critical word, four different conditions were created in both singular and plural form: correct condition, morphological violation, morphosyntactic violation, and combined violation, resulting in a total of eight sentences per critical word ( 4 conditions in singular and 4 in plural), for examples of stimulus conditions, see Table 1. Morphological violations were created by violating the word internal combinatorics, while preserving the grammatical markers. For example, in singular, the word 'lauta' (board) has two common stem allomorphs, 'lauta-' and a consonant-graded form 'lauda-', which both take a variety of inflectional suffixes. However, a certain suffix always requires a certain stem allomorph and vice versa; one can combine 'lauta' with suffixes -a (partitive case marker) and -an (illative case marker, meaning 'into somewhere') but not with suffixes -n (genitive case marker) and -sta (elative case, meaning 'out of somewhere'), which require the consonant-graded form 'lauda-'. Therefore, by combining a correct suffix (as requested by the preceding adjective) with an incorrect stem allomorph, we were able to create word internal morphological violations that did not affect the phrasal level morphosyntactic structure. To increase variation in the type of stem allomorphs presented in the experiment, we included the plural forms of the critical words in the stimuli. In plural stem allomorph + suffix morphological violations, the violations included stem allomorph changes or suffix changes (e.g., '*aavikko + iden' instead of 'aavikko + jen' ('of deserts') or '*lauta + iden' instead of 'lauto + jen' 'of boards'). All the stimuli were formed using these principles. Some of the critical words received 
Table 1

Examples of stimulus materials with non-literal interpretations and word-by-word translations into English.

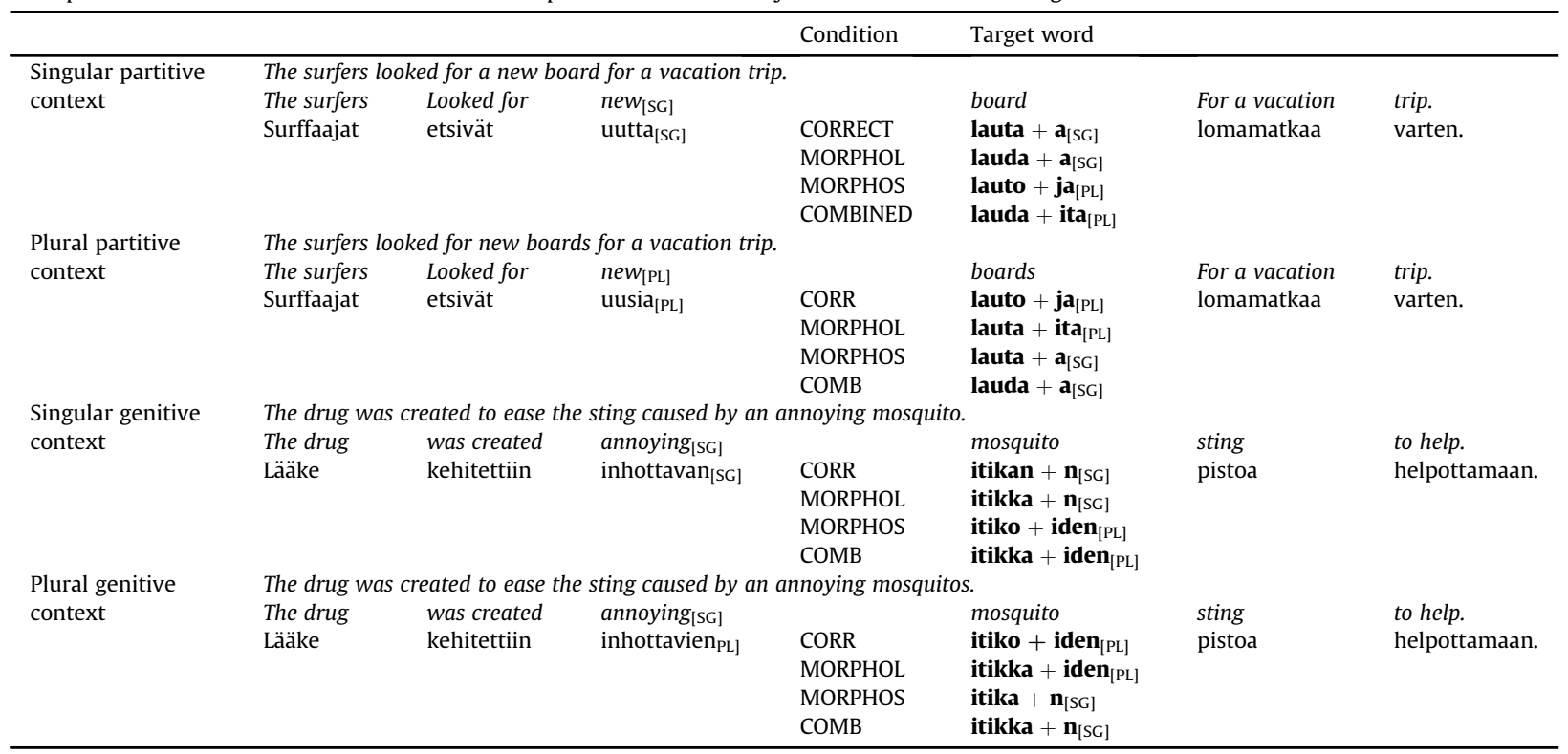

additional phonological changes so that the violated forms complied with Finnish phonotactics. ${ }^{4}$ Morphosyntactic violations consisted of number agreement violations between the critical word and the preceding adjective (e.g., uutta[SG] *lauto + ja [PL], new[SG] boards[PL]). Combined violations were realized by including both morphological and morphosyntactic violations simultaneously (see Table 1). The critical word was always the fourth word in the sentence. The sentences were pseudorandomly assigned to eight different lists, each containing only one variant from every context. Thus, each participant saw each variant only once. The stimulus conditions were evenly distributed; in every list, each condition was present in $25 \%$ of the sentences. Consequently, the distribution of plural and singular forms, as well as accusative and partitive forms, was counterbalanced. To match the amount of correct and incorrect sentences in the lists, 150 filler sentences - all in correct form - were added to the stimuli. The filler sentences had the same features and structure as the critical sentences. The lists of 450 sentences in total were randomized across the participants.

\subsection{Procedure}

The experiment consisted of 450 sentence trials. The stimulus presentation was commanded by a script written in Presentation 14.4 (Neurobehavioral Systems, Albany, NY, USA). All trials were randomly divided into five blocks and the block order between participants was pseudorandomized with reduced Latin square. Participants were asked to attend to the sentences and to avoid movements and excess blinking. A grammaticality judgment task was presented after approximately every fifth sentence. When prompted to respond, the participants were asked to indicate whether the previously presented sentence was an acceptable or unacceptable Finnish sentence. The participants responded by using a silent optical switch in which the participant's finger interrupted a modulated light beam. The participants lifted their right index finger if the sentence was acceptable and middle finger if the sentence was unacceptable. Each trial began with a 1000 ms inter-trial interval (ITI), followed by a fixation cross presented for $800 \mathrm{~ms}$, which was followed by the first word. The sentences were presented word by word with $800 \mathrm{~ms}$ SOA, such that every word was visible for $400 \mathrm{~ms}$, followed by 400 ms inter-stimulus interval (ISI) between each word. When a sentence ended with the prompt for an answer, a text "Answer now" appeared $1000 \mathrm{~ms}$ after the last word and was present for $1000 \mathrm{~ms}$. The experiment lasted for approximately one hour. Prior to the experiment, 10 practice trials were presented in order to familiarize the participant with the task. The viewing distance from the MEG device to the screen was about $60 \mathrm{~cm}$.

\subsection{Data recording}

The recordings took place in an electrically and magnetically shielded room (ETS-Lindgren Euroshield, Eura, Finland) with a Vectorview ${ }^{\mathrm{TM}}$ whole head MEG system (ElektaNeuromag, Elekta Ltd., Helsinki, Finland) in the BioMag Laboratory (HUSLAB,

\footnotetext{
4 All altered stems were existing stem allomorphs. Stem allomorphs have been found to have their own lexical representations (Järvikivi \& Niemi, 2002; Niemi et al., 1994), thus an interpretation of morphological violations as a simple orthographic violation is unlikely.
} 
Hospital District of Helsinki and Uusimaa, Helsinki, Finland). The 306-channel helmet-shaped system consists of 102 sensor elements each comprising two orthogonal planar gradiometers and one magnetometer. The EEG was recorded with a 60channel MEG compatible electrode cap (Easycap GmbH, Etterschlag, Germany) with pin type Ag/AgCl electrodes, using an amplifier inbuilt in the VectorView MEG system. Horizontal EOG was monitored with a bipolar electrode pair. The common recording reference electrode was placed to the nose and ground electrode to the right cheek. The head position inside the recording device was determined by four indicator coils in relation to the cardinal points of the head (nasion, left and right preaurical points), which were identified prior to the experiment with an Isotrak 3D-digitizer (Polhemus, Colchester, VT, USA). A sampling rate was set to $600 \mathrm{~Hz}$ and the EEG and MEG signals were online band-pass filtered to the frequency band from $0.03 \mathrm{~Hz}$ to $200 \mathrm{~Hz}$.

\subsection{Data analysis}

Raw MEG data were pre-processed offline with the spatiotemporal signal space separation (tSSS) algorithm of the MaxFilter software (ElektaNeuromag, Elekta Ltd., Helsinki, Finland). This was done prior to the main analysis in order to suppress any artifacts produced by nearby sources (e.g., the heart and dental braces) and external interference (e.g., line frequency noise) (Taulu \& Simola, 2006). BESA Research 5.3 Software (BESA GmbH, Munich, Germany) was used to process the raw EEG and the pre-processed MEG data. The data were offline band-pass filtered at $0.1-45 \mathrm{~Hz}$ and the EEG data were referenced offline to the average of the two mastoids. EEG channels with technical malfunction were replaced by interpolating the data of the surrounding electrode sites (Bendixen, Prinz, Horváth, Trujillo-Barreto, \& Schröger, 2008; Perrin, Pernier, Bertrand, \& Echallier, 1989). Artefacts caused by eye-blinks were corrected by using principal component analysis (PCA) (Ille, Berg, \& Scherg, 2002), an algorithm inbuilt in BESA software. Any remaining artefacts were removed automatically using $\pm 100 \mu \mathrm{V}$ rejection level for EEG data and $1200 \mathrm{fT} / \mathrm{cm}$ and $2000 \mathrm{fT}$ rejection level for gradiometers and magnetometers, respectively. The EEG and MEG responses time-locked to the stimulus onset were then epoched using a time window of $-100-800 \mathrm{~ms}$ with a pre-stimulus baseline correction of $-100-0 \mathrm{~ms}$. The number of remaining trials after artefact rejection was $76 \%$ for the correct, $77 \%$ for the morphosyntactic, $77 \%$ for the morphological, and $76 \%$ for the combined conditions.

\subsection{Source modeling}

To investigate the neural underpinnings of the effect of exposure to the different experimental conditions, we conducted distributed source estimations of the 204 gradiometer data. BESA 6.0 software (BESA Software GmbH, Munich, Germany) was used to run standardized, unweighted minimum norm source current estimate (sLORETA). Individual subject-level source estimations were calculated for each data point. These individual source images were averaged together for a group average image. A 4-shell standard spherical head model inbuilt in BESA Research 6.0 was used in the source reconstruction process.

\subsection{Statistical analysis}

Statistical analyses were performed using objective permutation tests using BESA Statistics 1.0 software (BESA Software $\mathrm{GmbH}$, Munich, Germany, for more information, see www.besa.de). The pair-wise statistical comparisons were performed for the EEG sensor space as well as MEG distributed source modeling data using parameter free cluster based permutation testing (Maris \& Oostenveld, 2007). The main idea of the permutation testing is that if a statistical effect is found over an extended time period in several neighboring channels, it is unlikely that this effect occurred by chance. Thus, the initial step is to define data clusters that show pronounced effects in the preliminary parametric tests. For each cluster, a cluster value can be derived consisting of the sum of all $\mathrm{t}$-values of all data points in the cluster. The clustering method is considered to be more suitable to study neural signals than analyses based on single data points in time and space. This is because it takes into account the natural origin of signals - long lasting and spatially larger effects are more probably caused by real neural sources, whereas short living and spatially constricted effects are less reliable. More specifically, first, a series of preliminary paired t-tests were computed that compared the ERP amplitudes and MEG neural source activation between the conditions (morphological vs. morphosyntactic violations, and each violation type vs. the correct condition) at every time point. Thereafter, significant values (with .05 significance level) were clustered together on the basis of their adjacency in time and space for ERPs (on a scalp plane) and 3D space for MEG sources (see below). The t-values for all points in the cluster were summed and for each cluster the data were randomly divided into subsets and a new summed $t$-value was determined. This was then repeated 1000 times (default), drawn randomly without repetitions from all possible permutations. In ERPs, the spatial neighbor distance was defined to be $4 \mathrm{~cm}$. No a priori defined time-windows for the analysis were used for the ERP data to maintain objectivity of the analysis. To reduce the number of free parameters in MEG-based sLORETA testing and to compensate for unreliability of a single voxel of source current estimate of a single time point, the neural source analysis was conducted by averaging source current estimates within the time-windows provided by the ERP cluster analysis. Clusters of source current estimates were thus defined only in 3D source space. The reported significances resulted from cluster level permutations and are thus insensitive to Type I error. 


\section{Results}

\subsection{Performance}

The mean percentage of correct responses to target sentences was 80\% (range 72-97\%), demonstrating that the participants understood the task well and concentrated on the stimuli.

\subsection{Signal space results (ERPS)}

Fig. 1 displays the spatiotemporal activation of the electric and magnetic activity in the different conditions across different time-windows. Fig. 2 illustrates the topographical distribution of the ERP responses in the time-windows where the significant differences between the conditions were observed, the time-course of spatial ROI distribution as well as significant clusters overlaid on topographic maps of the differences between correct and violation conditions (morphological vs. correct; morphosyntactic vs. correct; combined vs. correct).

The unbiased cluster-based permutation tests showed differences between the conditions in all the paired tests in the earlier (between 400 and $450 \mathrm{~ms}$ ) and later (between 600 and $800 \mathrm{~ms}$ ) time-windows (see Fig. 1B). Unbiased permutation tests showed that there were no significant effects before $390 \mathrm{~ms}$ after the stimulus onset.

The cluster-based permutation test revealed a significant difference between the morphological violation and the correct condition ( $\mathrm{p}=.02$ ) in the $409-431 \mathrm{~ms}$ time window, and the difference was most pronounced in the centro-parietal sensors. The morphological violation condition elicited larger N400-like negativity than the correct condition. The cluster-based statistics also revealed a significant difference between the morphosyntactic condition and the correct condition in the 390-443 ms time-window ( $\mathrm{p}=.003$ ), i.e. the morphosyntactic condition elicited a larger negativity than the correct condition. The difference was seen in left fronto-temporal sensors spreading also to centro-parietal channels, resembling the LAN and an additional N400-like negativity. There was also a significant difference between the combined and the correct

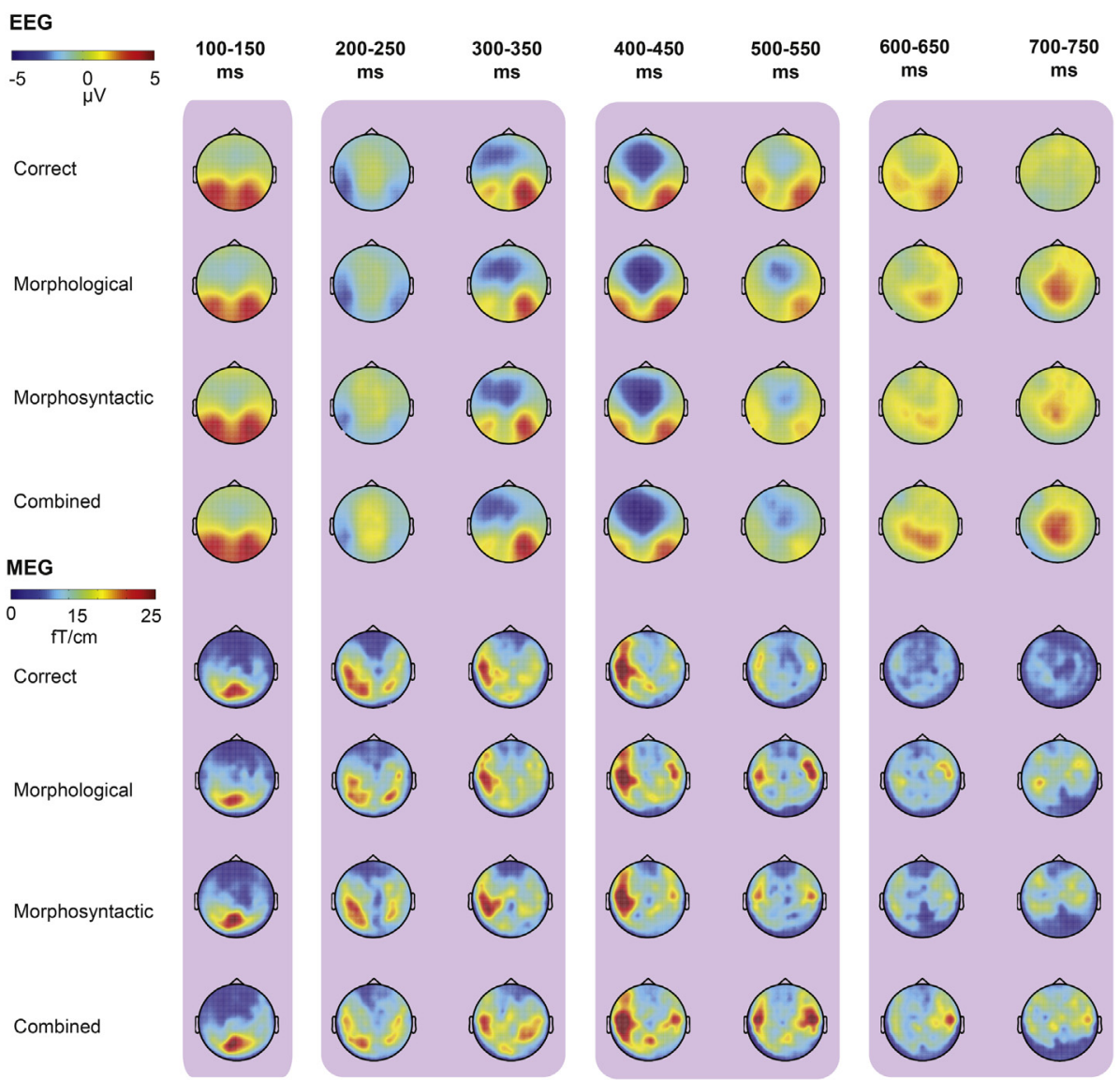

Fig. 1. Topographic maps of the grand average EEG and MEG sensor space activity for the different experimental conditions (correct, morphological, morphosyntactic, and combined) in $50 \mathrm{~ms}$ consecutive time-windows. 
A)

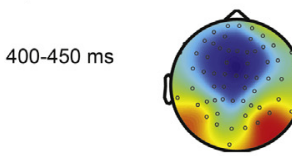

Correct

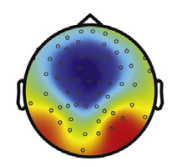

Morphological

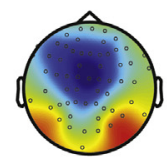

Morphosyntactic

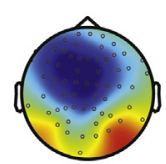

Combined
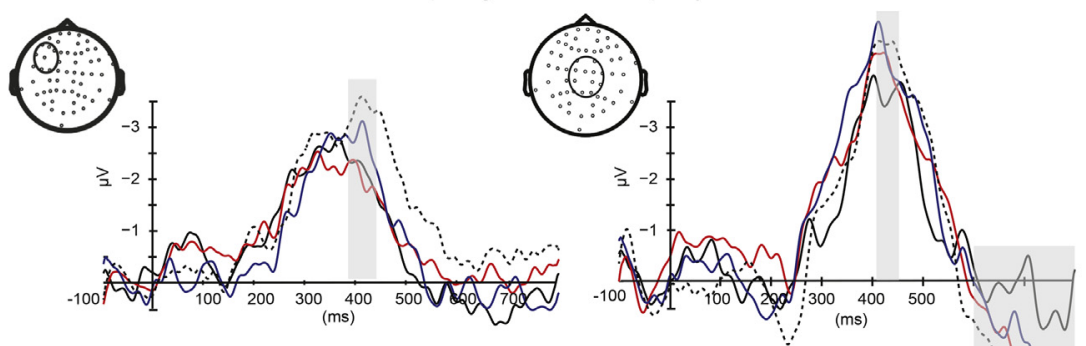

Morphosyntactic condition Morphological cond Combined condition

$600-800 \mathrm{~ms}$

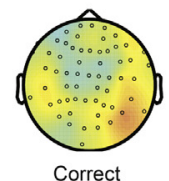

Correct

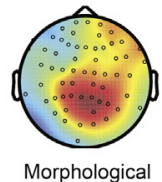

Morphological

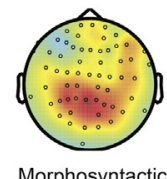

Morphosyntactic (ms

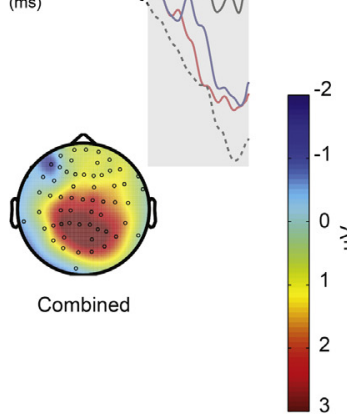

B)

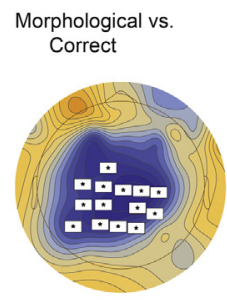

$409-431 \mathrm{~ms}$

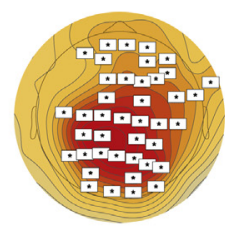

$621-800 \mathrm{~ms}$

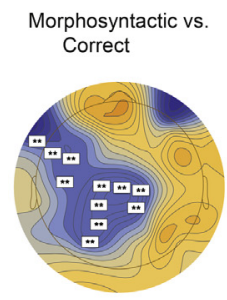

$390-443 \mathrm{~ms}$

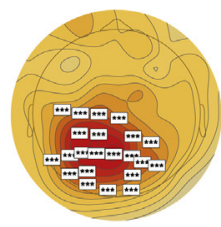

609-800ms

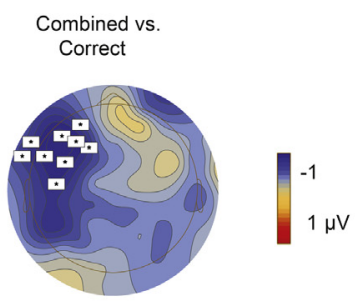

423-460ms

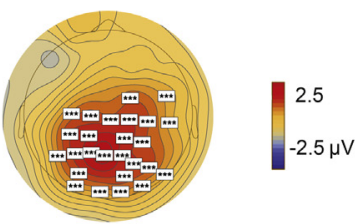

$641-800 \mathrm{~ms}$

Fig. 2. A) Topographic maps of the grand average ERP activity in the $400-450 \mathrm{~ms}$ and $600-800$ ms time-windows for the different experimental conditions (correct, morphological, morphosyntactic, and combined). Grand average ERPs from the left frontal and centro-parietal regions of interest (ROI) to all stimulus conditions. Gray bars show the time-windows where the significant effects were observed. The lines depict ERPs for the correct condition (black solid line), morphological condition (red solid line), morphosyntactic condition (blue solid line) and combined condition (black dotted line). Time 0 is the onset of the stimulus. Negativity is plotted upwards. The X-axis represents time (milliseconds, ms) and the Y-axis depicts voltage (microvolts, $\mu \mathrm{V}$ ); B) Grand average significant clusters overlaid on topographic maps of the difference between conditions (morphosyntactic vs. correct; morphological vs. correct; combined vs. correct). Channels belonging to the same significant cluster (ERP) are labeled by asterisks in the white boxes. The p-values are depicted by asterisks in both ERP electrodes and topographic maps $\left({ }^{*} \mathrm{p} \leq .05 ;{ }^{* *} \mathrm{p} \leq .01 ;{ }^{* * *} \leq .001\right)$. (For interpretation of the references to color in this figure legend, the reader is referred to the web version of this article.)

condition ( $\mathrm{p}=.015)$ in the $423-460 \mathrm{~ms}$ time-window. The difference was the largest in the left frontal sensors. The combined condition elicited a larger LAN-type of a negativity than the correct condition.

According to the cluster-based permutations, in the later time-window, all violation conditions differed from the correct condition: morphological vs. correct (621-800 ms, $\mathrm{p}=.001)$, morphosyntactic vs. correct (609-800 ms, $\mathrm{p}<.001$ ), combined vs. correct $(641-800 \mathrm{~ms}, \mathrm{p}<.001)$, i.e. all violation conditions elicited larger P600-like positivities than the correct condition. Topographically, the differences were most prominent in the centro-parietal sensors. 

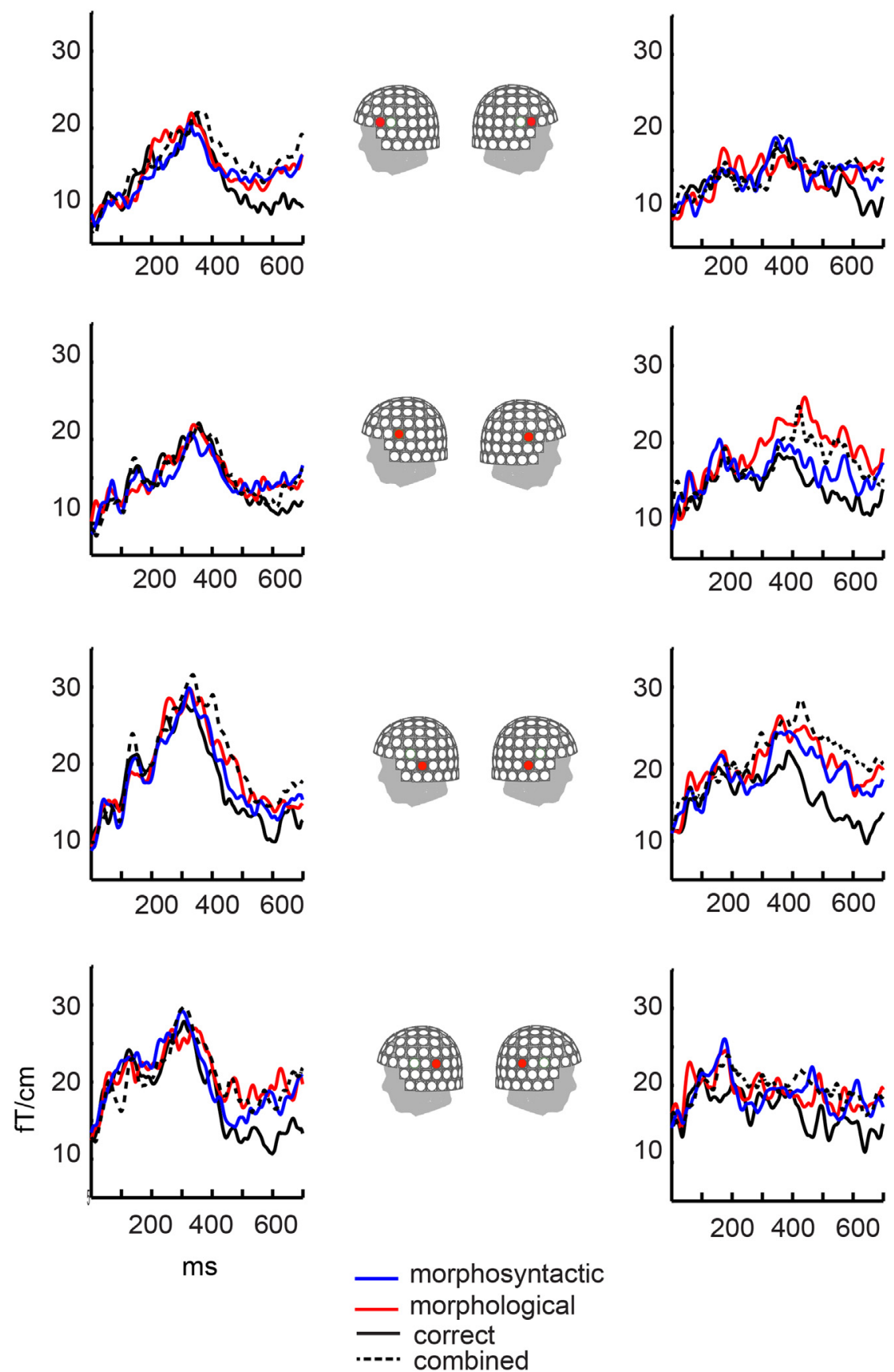

Fig. 3. Grand average event-related field (ERF) responses to the critical stimuli, i.e. the correct condition (black solid line), morphological condition (red solid line), morphosyntactic condition (blue solid line) and combined condition (black dotted line). The ERFs represent vector sums of two gradiometer pairs in the each hemisphere and region of interest. Vector sums were produced by computing the square root of the sum of squares of the two orthogonal planar gradiometers in each pair, i.e. by computing the absolute field gradient amplitude from the two orthogonal components. Left- and right side views of the MEG sensor array show the location of selected gradiometer pairs (marked in red). Time 0 is the onset of the stimulus. The X-axis represents time (milliseconds, ms) and the Y-axis depicts strength of the magnetic field (femtotesla per $\mathrm{cm}, \mathrm{fT} / \mathrm{cm}$ ). (For interpretation of the references to color in this figure legend, the reader is referred to the web version of this article.) 


\subsection{Source reconstruction based on $M E G$}

Fig. 3 presents the neuromagnetic signal strength of the left and right fronto-temporal gradiometers. Figs. 4 and 5 demonstrate overall topographical vector summed signal in gradiometer pairs and source activation as well as the source locations in which the significant differences between the conditions were observed.

Testing for the source activation differences in the latency range from 400 to 450 ms post stimulus, the cluster-based permutation test revealed a significant difference between the morphological violation and the correct condition $(\mathrm{p}=.007)$. The differences were most pronounced in the right anterior temporal area, where the morphological condition elicited larger source activation than the correct condition. In the same time-window, there were also differences between the morphosyntactic violation and the correct condition. The difference was most prominent in the left inferior frontal area $(\mathrm{p}=.042)$, i.e. the morphosyntactic condition elicited larger source activation than the correct condition. There was also a significant difference between the combined and correct condition in the left and right temporal $(p=.005)$ areas, with the combined condition eliciting larger source activation than the correct condition. There was also a significant difference between the morphosyntactic and morphological violations $(p=.045)$. The differences were largest in the left frontal cortices and there the morphosyntactic condition elicited larger source activation than the morphological violation condition.

Furthermore, in the 650-800 ms time-window, permutation tests revealed the difference between the morphological violation and the correct condition $(\mathrm{p}<.001)$, i.e. the morphological violation elicited larger source activation than the correct condition. The difference was most prominent in the bilateral fronto-temporal networks. There was also a difference between the morphosyntactic violation and the correct condition, i.e. the morpholosyntactic violation elicited larger source activation

A)

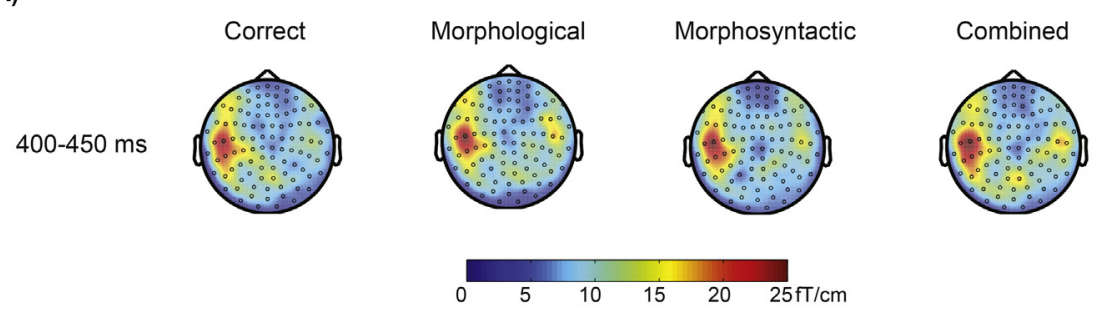

B)

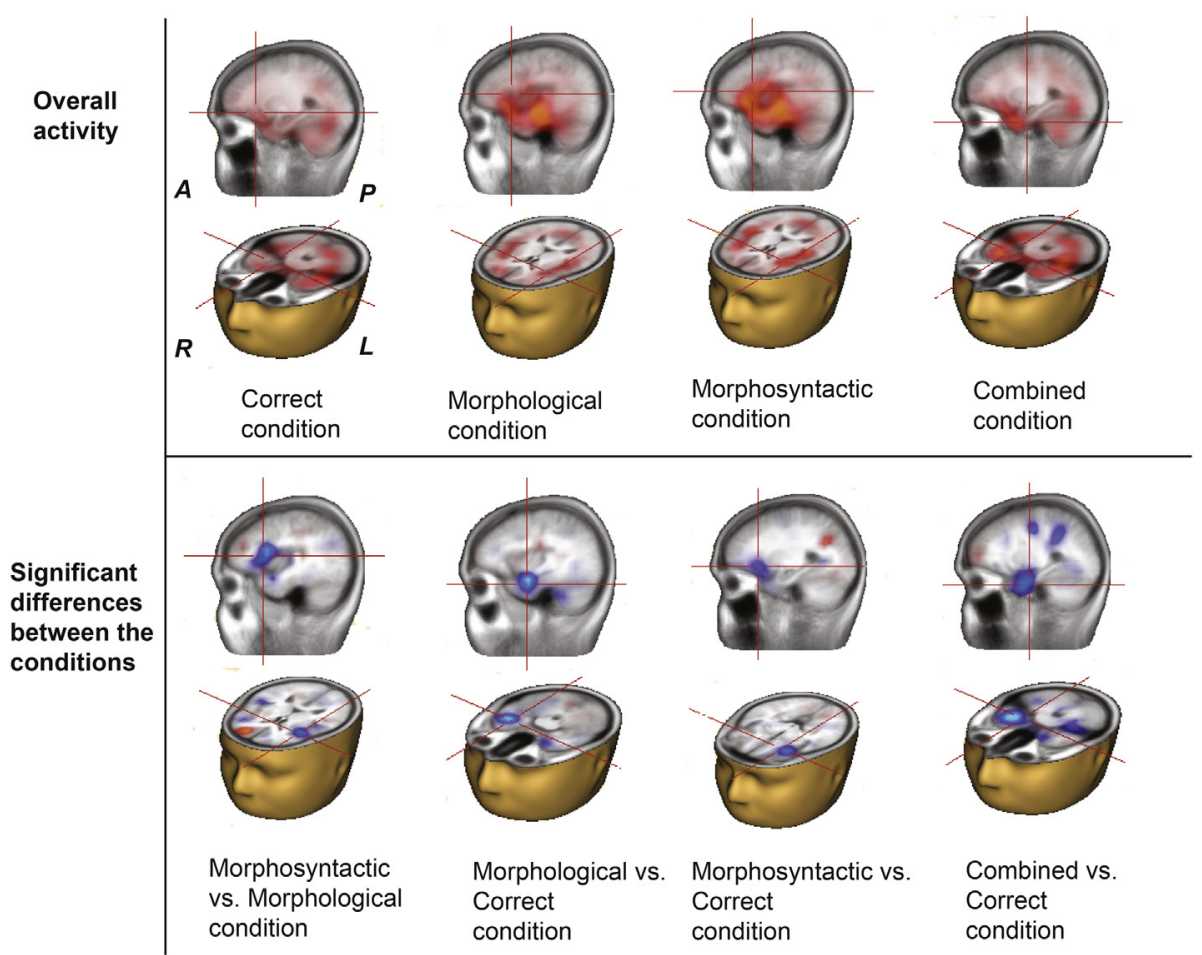

Fig. 4. A) Topographic maps and B) grand average sLORETA images on the planar gradiometer data for overall activity for different conditions as well as significant differences between the conditions (morphosyntactic vs. correct; morphological vs. correct; combined vs. correct; morphological) observed within the 400-450 ms time-window. 
A)

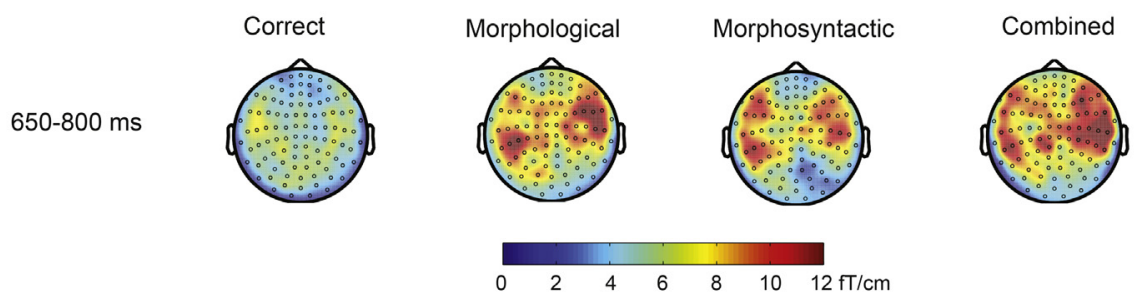

B)

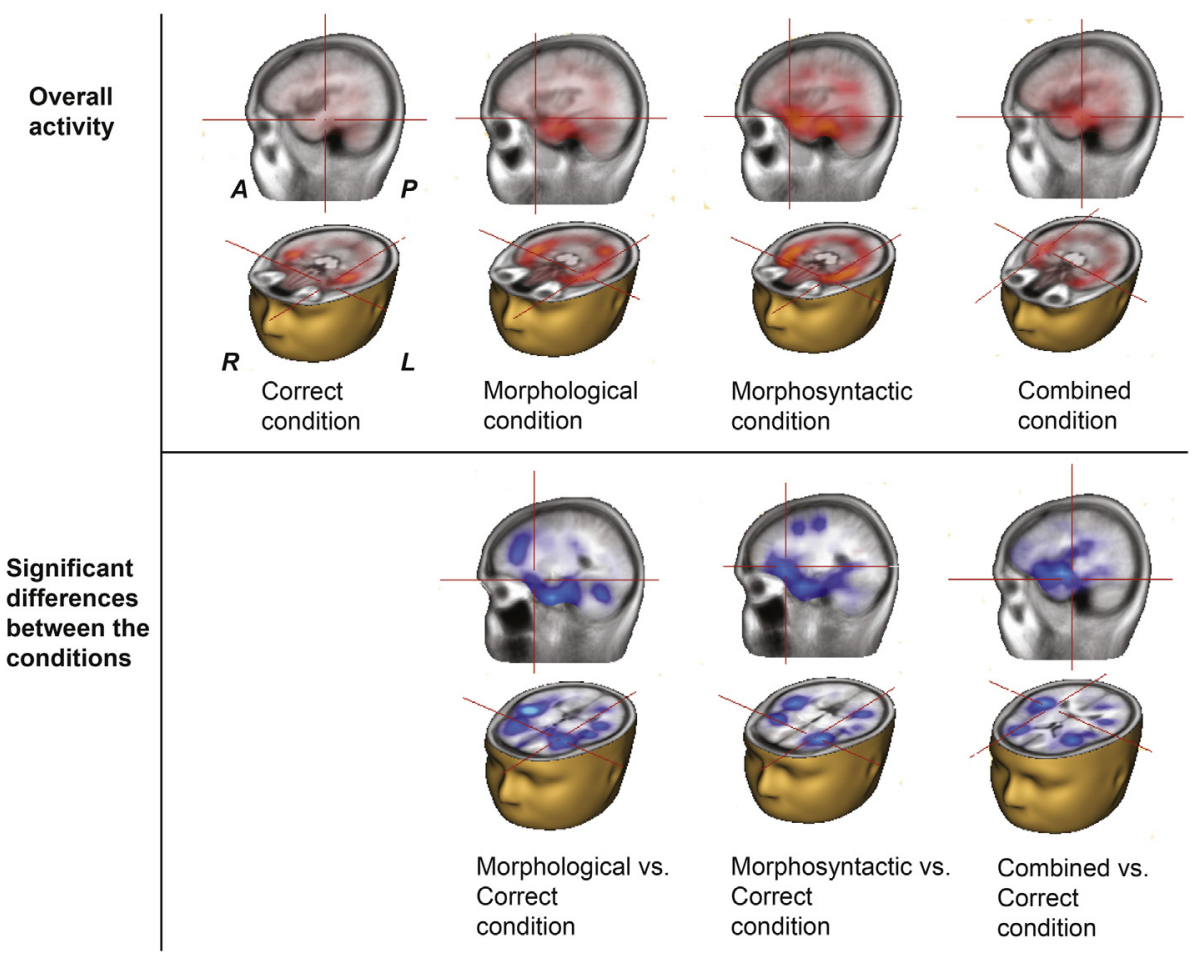

Fig. 5. A) Topographic maps and B) grand average sLORETA images on the planar gradiometer data for overall activity for different conditions and for significant differences between the conditions observed within the 650-800 ms time-window.

than the correct condition. The differences were most pronounced in the left frontal $(\mathrm{p}=.002)$ and right temporal $(\mathrm{p}<.001)$ areas. Moreover, the combined violation differed significantly from the correct condition $(p<.001)$, i.e. the combined violation elicited larger source activation than the correct condition. The differences were particularly pronounced bilaterally in the frontal areas as well as right temporal area. No significant differences were observed between the morphological and morphosyntactic conditions in this time range.

\section{Discussion}

We investigated the neural dynamics of phrase- and word-level morphological processing during sentence comprehension. In particular, we examined to what extent the neural generators underlying these parsing processes are overlapping or separate. To this end, we violated morphological rules of Finnish at the single word level (but in sentence context) and morphosyntactic rules at the phrase level. The two violation types occurred simultaneously in the combined violation condition (see Table 1). The morphological violation consisted of words with an existing stem allomorph and existing suffix, combined illegally, whereas the morphosyntactic violation included an adjective-noun case number violation. Our ERP results showed that the word-level morphological violation elicited a centro-parietal negativity, resembling rather an N400 than a LAN, as well as a parietal positivity (P600). Morphosyntactic violations elicited a left-lateralized anterior negativity resembling the LAN, which extended also to centro-parietal sensors, and which was followed by a P600 effect. The combined violation also elicited a negativity effect, which was significant and most prominent at the left anterior electrodes. The negativity was followed by a 
P600 effect also in this condition. Generally in line with previous findings (e.g., Marslen-Wilson \& Tyler, 2007), our neural source reconstruction demonstrated the involvement of the fronto-temporal cortical networks in morphological parsing processes. In the following, we will discuss the findings in more detail, focusing on each condition individually.

\subsection{Phrase-level parsing, morphosyntactic condition}

As mentioned above, the ERP results showed that morphosyntactic violations elicited the LAN, extending to centroparietal sensors, and the P600. The source analysis revealed activation of the fronto-temporal regions, with significant differences to the correct condition in the left inferior frontal cortical area. Only a few previous MEG studies have reported source localization of the LAN, and these have shown equivalent current dipole (ECD) activation in the left superior temporal cortex (Leminen et al., 2011; Service et al., 2007). Some MEG studies have localized the early left anterior negativity (ELAN) to the left inferior frontal and anterior temporal regions (Friederici, Wang, Herrmann, Maess, \& Oertel, 2000; Gross, Ioannides, et al., 1998). Moreover, several fMRI studies have reported the activation of the inferior frontal gyrus in relation with morphosyntactic agreement (Kovelman et al., 2008; Newman et al., 2003; Ni et al., 2000), and our results are in line with these findings.

One novel feature of the present study concerns the number agreement processing in relation to adjective-noun agreement. Previous ERP studies have investigated agreement processing mainly between subject and verb, determiner and noun, and, to a smaller extent, noun-adjective agreement structures in Romance languages (for a review, see Molinaro et al., 2011). Incorrect adjective-noun agreement violates the agreement requirement between two constituents belonging to the same syntactic element (noun phrase), whereas subject-verb agreement requires compatibility between two different syntactic elements (noun phrase and verb phrase). Our present finding suggests that morphosyntactic parsing and integration proceeds locally between any two adjacent constituents, and not only as a more global structure assignment processing. If the expected value is not met, an increased LAN activity reflects the detection of a mismatch. Leaning on this reasoning, the presently observed LAN (generated in the LIFG) may reflect the presence of neural populations responding to the local phrasal level structure building processes within a domain of case number agreement. Furthermore, eye-movement evidence on Finnish has suggested that agreement effect, e.g., between a modifier (adjective) and head noun, is likely to operate at the level of syntactic integration, i.e. when the parser integrates a combination of successive words into a complete phrase (Hyönä \& Vainio, 2009).

Spreading of the LAN to centro-parietal sensors may indicate the involvement of additional neural sources needed in demanding morphosyntactic parsing (see also Barber \& Carreiras, 2003). The combinatorial analysis in our study would thus include not only agreement mismatch resolution but also processes related to lexical-semantic demands, reflected in the additional centro-parietal negativity. Furthermore, according to one interpretation of agreement effects in Finnish, based on eye-movement evidence, when the language is morphologically complex, morphological information is an essential part of the initial structure building and parsing (Hyönä \& Vainio, 2009).

\subsection{Word-level parsing, morphological condition}

The processing of morphological violations elicited a centro-parietal N400-like negativity and a P600. We did not observe the anterior negativity for the morphological condition in the 400-450 ms time-window. Thus, even though we presented our stimuli in sentence contexts, our findings corroborate those by Lehtonen et al. (2007), who also did not find a clear LAN for a similar type of morphological violations in a lexical decision task. It thus seems that at least in this target language, visually presented inflected stimuli do not elicit a clear anterior but rather a more central negativity, regardless of whether they are presented in context or in isolation and of whether they are violated or correct. This is supported by several ERP and MEG studies using correctly inflected written Finnish words in single-word tasks which have reported larger N400/N400m effects for inflected words than for monomorphemic words (Lehtonen et al., 2007; Lehtonen et al., 2012; Leinonen et al., 2009; Leminen et al., 2011; Vartiainen, Aggujaro, et al., 2009). This N400/N400m effect in correctly inflected words has been taken to reflect a morphological processing cost related to integrating the decomposed lexical constituents at the syntactic-semantic level of processing, which is in line with processing architectures of models such as the Stem Allomorph/ Inflectional Decomposition (SAID) Model (Laine, M., Niemi, Koivuselkä-Sallinen, Ahlsén, \& Hyönä, 1994; Niemi, Laine, \& Tuominen, 1994) and the Interactive Activation Race model (Schreuder \& Baayen, 1995). According to these models, the recognition of inflected words involves morphological decomposition at the modality-specific input or access level (segmentation) and subsequent integration of meaning (composition) and syntactic features (licensing) of the morphological constituents. Following this line of thought, the increased N400 to morphological violations in our study is likely to reflect more demanding morphological processing related to integration of the illegally combined morphemes. Furthermore, since morphological violations contained an incorrect allomorph and suffix combination, this might have triggered an additional morphophonological analysis apart from morphological morpheme segmentation and integration. Although ERP/MEG studies on morphophonological analysis are scarce, existing evidence suggests that some individuals may show an early N400 effect during morphophonological parsing (Steinhauer \& Ullman, 2002). Our findings are in line with this previous evidence.

The N400 effect observed for the morphological condition in the present study is later than the effects (before 300 ms post stimulus onset) typically observed in ERP/MEG studies using masked morphological priming (Morris, Frank, Grainger, \& Holcomb, 2007; Morris, Grainger, \& Holcomb, 2013; Morris \& Stockall, 2012). Such findings have been attributed to the 
morpho-orthographic segmentation stage, i.e., the early phase of visual word recognition in which the visual word forms of stems and affixes are initially activated. As concluded above, the current N400 results, in turn, are assumed to reflect a process of semantic-syntactic integration of the morphological constituents, instead of the early activation of the morphemes (see, e.g., Lehtonen et al., 2007). Earlier effects of morphology have been less typical findings when using a non-priming paradigm. Thus, here we refer to "early" effects as those prior to P600 effects, i.e., N400 or LAN effects.

Neural source reconstruction analysis demonstrated wide-spread bilateral activation for morphological violation, with significant differences between the morphological and correct conditions, being most prominent in the right temporal area in the N400 time-window. Previous MEG studies have localized the N400 to the left and right superior temporal areas (D'Arcy, Connolly, Service, Hawco, \& Houlihan, 2004; Dhond, Witzel, Dale, \& Halgren, 2007; Frishkoff, Tucker, Davey, \& Scherg, 2004; Helenius et al., 2002; Maess, Herrmann, Hahne, Nakamura, \& Friederici, 2006; Service et al., 2007; Uusvuori et al., 2008; Vartiainen, Parviainen, et al., 2009) as well as the middle/anterior temporal and inferior frontal areas (Halgren et al., 2002; Kutas \& Federmeier, 2011). The processing of correctly inflected words has previously been shown to activate the left inferior frontal gyrus and superior temporal cortices (Laine et al., 1999; Lehtonen et al., 2006; Leminen, Leminen, Kujala, \& Shtyrov, 2013; Leminen et al., 2011; Tyler et al., 2005; Vartiainen, Aggujaro, et al., 2009). The involvement of temporal areas in morphological stem allomorph + suffix violation processing is thus generally in line with the previous findings for inflected word processing. The increased right hemisphere activity for the morphological violation in comparison with the correct condition may be related to increased semantic integration demands and/or additional morphophonological analysis or an incorrect stem allomorph + suffix combination, which is purportedly governed by temporo-parietal cortical networks (e.g., Steinhauer \& Ullman, 2002). There are findings that semantic processing often involves also the right hemisphere, e.g. during the processing of figurative language (for a review, see e.g., Lindell, 2006) and during an increase in semantic complexity (Tremblay, Monetta, \& Joanette, 2009). Increased semantic complexity might index a right hemisphere's allocation of additional attentional resources needed for effortful processing (Monetta, Ouellet-Plamondon, \& Joanette, 2006). One may also speculate that the spreading of activation to the right hemisphere, often assumed to have a role in pragmatic aspects of language, could reflect a search for an alternative interpretation and recheck of the illegal morpheme combination.

\subsection{The combined violation condition}

In this condition, in ERPs, we observed an earlier negativity and a late positivity (P600) effect. The negativity was particularly prominent in the left anterior electrodes. In source modeling, the difference between the combined and correct condition was significant in the right temporal cortex. Interestingly, the combined violation condition seems to partly and simultaneously activate the neural networks involved in both single violation conditions separately. As discussed above, the occurrence of both the anterior and central negativities in the morphosyntactic condition suggests the involvement of both word-level morphological and phrase-level morphosyntactic parsing processes. In the combined condition, however, the morphosyntactic analysis seems to be dominant at the ERP level, as the centro-parietal negativity was not significant in ERPs. The source reconstruction of the MEG data, however, showed a wide-spread bilateral activity but the differences as compared with the correct condition were most prominent in the bilateral temporal networks in the N400 time-window. Why do ERP data and MEG source modeling data seem to show somewhat different neural activation patterns in the combined violation condition as compared to the single violations? The sensitivity fields of EEG and MEG are different, i.e., these methods are differentially sensitive to projections of the same neural source signals. Hence, some neural sources show significant activity difference more easily only in one of the methods. Due to the same reason, they also sum together spatial source distributions in a different manner, which may lead to different results in EEG and MEG, if some sources cancel each other out in one of the methods. The distributed source analysis method used in our study partly assists in combining these two methods, as it sums together the absolute amount of source activity within a spatial cluster and integrates sources with a slightly different orientation. Combined evidence from both methods can therefore be assumed to provide us with a more comprehensive picture of the underlying linguistic processes. The single violation conditions showed differences both in sensor space and source reconstruction data, based on which we can assume that the neural networks involved in the processing of violations of word-level and phrase-level morphological rules are at least partially distinct. Taken all our evidence together, the LAN effect (more robustly seen in ERPs) is more systematically associated with a phrase level morphosyntactic violation, whereas the right temporal activity (measurable more accurately in the MEG source level) is more systematically associated with morphological violation.

Furthermore, it is worth noting that all violation conditions elicited larger P600 effects than the correct condition. This finding is in correspondence with the P600 elicited during morphosyntactic agreement processing (for a review, see Molinaro et al., 2011). The results are also in line with the P600 observed during the processing of morphological and inflectional agreement violations in sentence contexts (Allen, Badecker, \& Osterhout, 2003; Leinonen et al., 2008; Lück, Hahne, \& Clahsen, 2006; Morris \& Holcomb, 2005; Newman et al., 2007; Rodríguez-Fornells et al., 2001). The P600 in relation to morphosyntax has often been interpreted as reflecting reanalysis or repair of the violated context, as target words that are ungrammatical in the light of the preceding sentence context have been systematically shown to elicit a P600 (Coulson, King, \& Kutas, 1998; Friederici, 2002; Friederici \& Weissenborn, 2007; Morris \& Holcomb, 2005; Münte et al., 1997). Interestingly, however, the P600 effect has also been elicited without sentence contexts during the processing of morphological violations in single words (Lehtonen et al., 2007; Morris \& Holcomb, 2005) and with correctly inflected words (e.g., Lehtonen et al., 2007) and syntactically correct sentences (e.g., Kaan, Harris, Gibson, \& Holcomb, 2000). Thus, the P600 has also been proposed to index 
morphosyntactic integration difficulty (Carreiras, Salillas, \& Barber, 2004; Kaan et al., 2000) and integration processes during normal agreement computations (Mancini et al., 2011; Molinaro et al., 2011). The current study contributes to the understanding of the P600 via the systematic assessment of the neural sources of this assumed combinatorial process of reanalysis and integration. In our study, the overall source activation showed the involvement of the bilateral fronto-temporal cortical networks. The morphological condition elicited a larger activation of the bilateral fronto-temporal areas than the correct condition. The morphosyntactic condition elicited larger activation than the correct condition in the left frontal and right temporal areas. In the combined vs. correct condition, significant differences were observed in the bilateral frontal and right temporal sources. There are very few previous studies on the neural generators of the P600 effect, but in those the P600 has been localized to the bilateral temporal areas (Service et al., 2007) and to bilateral frontal, posterior temporal, and parietal regions (Kielar et al., 2014). The P600 has been proposed to arise from the interaction of the neural processes in the left inferior frontal gyrus and left posterior middle temporal gyrus during syntactic reinterpretation (Tyler et al., 2011). The involvement of a wider bilateral fronto-temporal network fits the proposal that the temporal cortex together with the inferior frontal area are relevant for semantic-syntactic combinatorial processes during sentence integration (e.g., Tyler et al., 2011). Importantly, in our study, there were no significant differences between the morphosyntactic and morphological conditions in the P600, indicating that the neural sources of this brain response in the two conditions were overlapping. This suggests that at least with the present stimuli, there is a common neural generator involved in the combinatorial morphological and morphosyntactic analysis in the later, integrative and repairing (in the case of incorrect stimuli) stages of processing.

\subsection{Summary and conclusions}

The current study presents novel findings on the spatiotemporal dynamics of phrase-level (morphosyntactic) and wordlevel (morphological) parsing processes. The main finding was that morphosyntactic and morphological parsing are underpinned by networks in the fronto-temporal cortices, involving however, different subnetworks (i.e., to some extent different neural populations). Based on the signal space and source reconstruction, checking the compatibility of adjacent elements within a word (here stem and suffix) is reflected in the bilateral N400-like negativity, whose sources are localized most prominently to the right temporal area. Within the same time frame (400-450 ms), the parser checks the compatibility of the two adjacent elements within a phrase, in this case, the inflection (plural and singular number) of the adjective and the noun (morphosyntactic parsing). A violation in this process is indexed by the LAN effect, whose sources are generated in the left frontal cortical networks. The phrase-level parsing also seems to recruit partly similar processes to those involved in word-level integration, reflected in the centro-parietal negativity in the ERPs. Processing of simultaneous word-level and phrase-level violations activates bilaterally frontal and anterior temporal areas, which seem to be the combination of both of the single violations. That is, the LAN-type response was observed in ERPs, whereas the N400-like source activity was found in the MEG source reconstruction. Our results suggest that in the earlier time frame there are subnetworks within the frontotemporal cortices that underpin word- and phrase-level parsing differently. In the later time frame, the processing of single word- and phrase-level violations, as well as the combined violation, elicited P600 effects. The neural sources of the P600 did not differ between the morphosyntactic and morphological conditions, suggesting that this later processing stage engages largely similar neural resources.

Our results suggest that the parser checks and integrates semantic-syntactic properties of single inflected words particularly in the temporal cortices. Within the same time frame, the separate neural subnetwork, involving the left inferior frontal area, checks the compatibility of inflectional features between the two adjacent elements within a phrase. Further in the analysis, a larger network of fronto-temporal areas integrates the elements into a structurally organized sentence representation. We propose that at the earlier processing stage, word- and phrase level combinatorial analyses involve to some extent different neural recruitment, with considerable overlap in the later, more global integrative processing stages.

\section{Acknowledgments}

This study was supported by HUSLAB, the Academy of Finland (project 137511), Lundbeck Foundation (Grant 2013-12951), Ella and Georg Ehrnrooth foundation personal grants to the first and last authors; a KONE foundation project grant to the first author, as well as an Emil Aaltonen Foundation project grant and University of Helsinki 3-year grants to the last author.

\section{References}

Allen, M., Badecker, W., \& Osterhout, L. (2003). Morphological analysis in sentence processing: an ERP study. Language and Cognitive Processes, 18, 405-430.

Angrilli, A., Penolazzi, B., Vespignani, F., De Vincenzi, M., Job, R., Ciccarelli, L., et al. (2002). Cortical brain responses to semantic incongruity and syntactic violation in Italian language: an event-related potential study. Neuroscience Letters, 322, 5-8.

Baayen, R. H., Milin, P., Durdevic, D. F., Hendrix, P., \& Marelli, M. (2011). An amorphous model for morphological processing in visual comprehension based on naive discriminative learning. Psychological Reviews, 118, 438-481.

Barber, H., \& Carreiras, M. (2003). Integrating gender and number information in Spanish word pairs: an ERP study. Cortex, 39, 465-482.

Barber, H., \& Carreiras, M. (2005). Grammatical gender and number agreement in Spanish: an ERP comparison. Journal of Cognitive Neuroscience, 17, $137-153$.

Bendixen, A., Prinz, W., Horváth, J., Trujillo-Barreto, N. J., \& Schröger, E. (2008). Rapid extraction of auditory feature contingencies. Neurolmage, 41, $1111-1119$. 
Bornkessel, I., \& Schlesewsky, M. (2006). The extended argument dependency model: a neurocognitive approach to sentence comprehension across languages. Psychological Review, 113, 787-821.

Bozic, M., \& Marslen-Wilson, W. D. (2010). Neurocognitive context for morphological complexity: dissociating inflection and derivation. Language and Linguistics Compass, 4, 1063-1073.

Carreiras, M., Pattamadilok, C., Meseguer, E., Barber, H., \& Devlin, J. T. (2012). Broca's area plays a causal role in morphosyntactic processing. Neuropsychologia, 50, 816-820.

Carreiras, M., Salillas, E., \& Barber, H. (2004). Event-related potentials elicited during parsing of ambiguous relative clauses in Spanish. Brain Research Cognitive Brain Research, 20, 98-105.

Clahsen, H. (1999). Lexical entries and rules of language: a multidisciplinary study of German inflection. Behavioral and Brain Sciences, 22, 991-1060.

Coulson, S., King, J. F., \& Kutas, M. (1998). Expect the unexpected: event-related brain response to morphosyntactic violations. Language and Cognitive Processes, 13, 21-58.

D'Arcy, R. C., Connolly, J. F., Service, E., Hawco, C. S., \& Houlihan, M. E. (2004). Separating phonological and semantic processing in auditory sentence processing: a high-resolution event-related brain potential study. Human Brain Mapping, 22, 40-51.

Deutsch, A., \& Bentin, S. (2001). Syntactic and semantic factors in processing gender agreement in Hebrew: evidence from ERPs and eye movements. Journal of Memory and Language, 200-224.

Dhond, R. P., Witzel, T., Dale, A. M., \& Halgren, E. (2007). Spatiotemporal cortical dynamics underlying abstract and concrete word reading. Human Brain Mapping, 28, 355-362.

Federmeier, K. D., Segal, J. B., Lombrozo, T., \& Kutas, M. (2000). Brain responses to nouns, verbs and class-ambiguous words in context. Brain, 123, $2552-2566$.

Friederici, A. D. (2002). Towards a neural basis of auditory sentence processing. Trends in Cognitive Sciences, 6, $78-84$.

Friederici, A. D., \& Kotz, S. A. (2003). The brain basis of syntactic processes: functional imaging and lesion studies. NeuroImage, 20 , S8-S17.

Friederici, A. D., Wang, Y., Herrmann, C. S., Maess, B., \& Oertel, U. (2000). Localization of early syntactic processes in frontal and temporal cortical areas: a magnetoencephalographic study. Human Brain Mapping, 11, 1-11.

Friederici, A. D., \& Wartenburger, I. (2010). Language and brain. Wiley Interdisciplinary Reviews: Cognitive Science, 1, 150-159.

Friederici, A. D., \& Weissenborn, J. (2007). Mapping sentence form onto meaning: the syntax-semantic interface. Brain Research, 1146, 50-58.

Frishkoff, G. A., Tucker, D. M., Davey, C., \& Scherg, M. (2004). Frontal and posterior sources of event-related potentials in semantic comprehension. Brain Research Cognitive Brain Research, 20, 329-354.

Gonnerman, L. M., Seidenberg, M. S., \& Andersen, E. S. (2007). Graded semantic and phonological similarity effects in priming: evidence for a distributed connectionist approach to morphology. Journal of Experimental Psychology: General, 136, 323-345.

Grodzinsky, Y., \& Friederici, A. D. (2006). Neuroimaging of syntax and syntactic processing. Current Opinion in Neurobiology, $16,240-246$.

Gross, J., Ioannides, A. A., Dammers, J., Maess, B., Friederici, A. D., \& Muller-Gartner, H. W. (1998). Magnetic field tomography analysis of continuous speech. Brain Topography, 10, 273-281.

Gross, M., Say, T., Kleingers, M., Clahsen, H., \& F.Münte, T. (1998). Human brain potentials to violations in morphologically complex Italian words. Neuroscience Letters, 241, 83-86.

Gunter, T. C., Stowe, L. A., \& Mulder, G. (1997). When syntax meets semantics. Psychophysiology, 34, 660-676.

Hagoort, P. (2003). Interplay between syntax and semantics during sentence comprehension: ERP effects of combining syntactic and semantic violations. Journal of Cognitive Neuroscience, 15, 883-899.

Hagoort, P., Baggio, G., \& Willems, R. M. (2009). Semantic unification. In M. S. Gazzaniga (Ed.), The cognitive neurosciences (Vol. Fourth, pp. 819-837). Cambridge, Massachusets: MIT Press.

Halgren, E., Dhond, R. P., Christensen, N., Van Petten, C., Marinkovic, K., Lewine, J. D., et al. (2002). N400-like magnetoencephalography responses modulated by semantic context, word frequency, and lexical class in sentences. Neurolmage, 17, 1101-1116.

Helenius, P., Salmelin, R., Service, E., Connolly, J. F., Leinonen, S., \& Lyytinen, H. (2002). Cortical activation during spoken-word segmentation in nonreadingimpaired and dyslexic adults. Journal of Neuroscience, 22, 2936-2944.

Hyönä, J., \& Vainio, S. (2009). Sentence parsing in a morphologically rich language-Finnish. Language and Linguistics Compass, 3, 719-733.

Ille, N., Berg, P., \& Scherg, M. (2002). Artifact correction of the ongoing EEG using spatial filters based on artifact and brain signal topographies. Journal of Clinical Neurophysiology, 19, 113-124.

Järvikivi, J., \& Niemi, J. (2002). Form-based representation in the mental lexicon: priming (with) bound stem allomorphs in Finnish. Brain and Language, 81, $412-423$.

Kaan, E., Harris, A., Gibson, E., \& Holcomb, P. J. (2000). The P600 as an index of syntactic integration difficulty. Language and Cognitive Processes, 15.

Kielar, A., Panamsky, L., Links, K. A., \& Meltzer, J. A. (2014). Localization of electrophysiological responses to semantic and syntactic anomalies in language comprehension with MEG. Neurolmage, 105, 507-524.

Kiparsky, P. (2001). Structural case in Finnish. Lingua, 111, 315-376.

Kovelman, I., Baker, S. A., \& Petitto, L. A. (2008). Bilingual and monolingual brains compared: a functional magnetic resonance imaging investigation of syntactic processing and a possible "neural signature" of bilingualism. Journal of Cognitive Neuroscience, 20, $153-169$.

Krott, A., Baayen, R. H., \& Hagoort, P. (2006). The nature of anterior negativities caused by misapplications of morphological rules. Journal of Cognitive Neuroscience, $18,1616-1630$.

Kuperberg, G. R. (2007). Neural mechanisms of language comprehension: challenges to syntax. Brain Research, 1146, 23-49.

Kutas, M., \& Federmeier, K. D. (2000). Electrophysiology reveals semantic memory use in language comprehension. Trends in Cognitive Sciences, 4, 463-470.

Kutas, M., \& Federmeier, K. D. (2011). Thirty years and counting: finding meaning in the N400 component of the event-related brain potential (ERP). Annual Reviews in Psychology, 62, 621-647.

Laine, M., Niemi, J., Koivuselkä-Sallinen, P., Ahlsén, E., \& Hyönä, J. (1994). A neurolinguistic analysis of morphological deficits in a Finnish-Swedish bilingual aphasic. Clinical Linguistics \& Phonetics, 8, 177-200.

Laine, M., Rinne, J. O., Krause, B. J., Teräs, M., \& Sipilä, H. (1999). Left hemisphere activation during processing of morphologically complex word forms in adults. Neuroscience Letters, 271, 85-88.

Laine, M., \& Virtanen, P. (1999). WordMill lexical search program. Centre for Cognitive Neuroscience. University of Turku.

Lau, E., Almeida, D., Hines, P. C., \& Poeppel, D. (2009). A lexical basis for N400 context effects: evidence from MEG. Brain and Language, 111, 161-172.

Lau, E., Phillips, C., \& Poeppel, D. (2008). A cortical network for semantics: (de)constructing the N400. Nature Reviews Neuroscience, 9, 920-933.

Lehtonen, M., Cunillera, T., Rodriguez-Fornells, A., Hulten, A., Tuomainen, J., \& Laine, M. (2007). Recognition of morphologically complex words in Finnish: evidence from event-related potentials. Brain Research, 1148, 123-137.

Lehtonen, M., Hulten, A., Rodriguez-Fornells, A., Cunillera, T., Tuomainen, J., \& Laine, M. (2012). Differences in word recognition between early bilinguals and monolinguals: behavioral and ERP evidence. Neuropsychologia, 50, 1362-1371.

Lehtonen, M., \& Laine, M. (2003). How word frequency affects morphological processing in bilinguals and monolinguals. Bilingualism: Language and Cognition, 6, 213-225.

Lehtonen, M., Vorobyev, V. A., Hugdahl, K., Tuokkola, T., \& Laine, M. (2006). Neural correlates of morphological decomposition in a morphologically rich language: an fMRI study. Brain and Language, 98, 182-193.

Lehtonen, M., Vorobyev, V., Soveri, A., Hugdahl, K., Tuokkola, T., \& Laine, M. (2009). Language-specific activations in the brain: evidence from inflectional processing in bilinguals. Journal of Neurolinguistics, 22, 495-513.

Leinonen, A., Brattico, P., Järvenpää, M., \& Krause, C. M. (2008). Event-related potential (ERP) responses to violations of inflectional and derivational rules of Finnish. Brain Research, 1218, 181-193. 
Leinonen, A., Grönholm-Nyman, P., Järvenpää, M., Söderholm, C., Lappi, O., Laine, M., et al. (2009). Neurocognitive processing of auditorily and visually presented inflected words and pseudowords: evidence from a morphologically rich language. Brain Research, 1275, 54-66.

Leminen, A., Leminen, M., Kujala, T., \& Shtyrov, Y. (2013). Neural dynamics of inflectional and derivational morphology processing in the human brain. Cortex, 49, 2758-2771.

Leminen, A., Leminen, M., Lehtonen, M., Nevalainen, P., Ylinen, S., Kimppa, L., et al. (2011). Spatiotemporal dynamics of the processing of spoken inflected and derived words: a combined EEG and MEG study. Frontiers in Human Neuroscience, 5, 1-14.

Linares, R., Rodriguez-Fornells, A., \& Clahsen, H. (2006). Stem allomorphy in the Spanish mental lexicon: evidence from behavioral and ERP experiments. Brain and Language, 97, 110-120.

Lindell, A. K. (2006). In your right mind: right hemisphere contributions to language processing and production. Neuropsychological Reviews, 16, 131-148.

Lück, M., Hahne, A., \& Clahsen, H. (2006). Brain potentials to morphologically complex words during listening. Brain Research, 1077, $144-152$.

Maess, B., Herrmann, C. S., Hahne, A., Nakamura, A., \& Friederici, A. D. (2006). Localizing the distributed language network responsible for the N400 measured by MEG during auditory sentence processing. Brain Research, 1096, 163-172.

Mancini, S., Molinaro, N., Rizzi, L., \& Carreiras, M. (2011). A person is not a number: discourse involvement in subject-verb agreement computation. Brain Research, 1410, 64-76.

Maris, E., \& Oostenveld, R. (2007). Nonparametric statistical testing of EEG- and MEG-data. Journal of Neuroscience Methods, 164, 177-190.

Marslen-Wilson, W. D., \& Tyler, L. K. (2007). Morphology, language and the brain: the decompositional substrate for language comprehension. Philosophical Transactions of the Royal Society B: Biological Sciences, 362, 823-836.

Molinaro, N., Barber, H. A., \& Carreiras, M. (2011). Grammatical agreement processing in reading: ERP findings and future directions. Cortex, 47, $908-930$.

Molinaro, N., Carreiras, M., \& Dunabeitia, J. A. (2012). Semantic combinatorial processing of non-anomalous expressions. NeuroImage, 59, 3488-3501.

Molinaro, N., Vespignani, F., \& Job, R. (2008). A deeper reanalysis of a superficial feature: an ERP study on agreement violations. Brain Research, 1228, $161-176$.

Monetta, L., Ouellet-Plamondon, C., \& Joanette, Y. (2006). Simulating the pattern of right-hemisphere-damaged patients for the processing of the alternative metaphorical meanings of words: evidence in favor of a cognitive resources hypothesis. Brain and Language, 96, $171-177$.

Morris, J., Frank, T., Grainger, J., \& Holcomb, P. J. (2007). Semantic transparency and masked morphological priming: an ERP investigation. Psychophysiology, 44, 506-521.

Morris, J., Grainger, J., \& Holcomb, P. J. (2013). Tracking the consequences of morpho-orthographic decomposition using ERPs. Brain Research, $1529,92-104$.

Morris, J., \& Holcomb, P. J. (2005). Event-related potentials to violations of inflectional verb morphology in English. Cognitive Brain Research, 25, 963-981.

Morris, J., \& Stockall, L. (2012). Early, equivalent ERP masked priming effects for regular and irregular morphology. Brain and Language, 123, 81-93.

Münte, T. F., Matzke, M., \& Johannes, S. (1997). Brain activity associated with syntactic incongruencies in words and pseudo-words. Journal of Cognitive Neuroscience, 9, 318-329.

Newman, S. D., Just, M. A., Keller, T. A., Roth, J., \& Carpenter, P. A. (2003). Differential effects of syntactic and semantic processing on the subregions of Broca's area. Brain Research Cognitive Brain Research, 16, 297-307.

Newman, A., Ullman, M., Pancheva, R., Waligura, D., \& Neville, H. (2007). An ERP study of regular and irregular English past tense inflection. NeuroImage, 34, 435-445.

Ni, W., Constable, R. T., Mencl, W. E., Pugh, K. R., Fulbright, R. K., Shaywitz, S. E., et al. (2000). An event-related neuroimaging study distinguishing form and content in sentence processing. Journal of Cognitive Neuroscience, 12, 120-133.

Niemi, J., Laine, M., \& Tuominen, J. (1994). Cognitive morphology in Finnish: foundations of a new model. Language and Cognitive Processes, 9, $423-446$.

Oldfield, R. C. (1971). The assessment and analysis of handedness: the Edinburgh inventory. Neuropsychologia, 9, 97-113.

Palolahti, M., Leino, S., Jokela, M., Kopra, K., \& Paavilainen, P. (2005). Event-related potentials suggest early interaction between syntax and semantics during on-line sentence comprehension. Neuroscience Letters, 384, 222-227.

Penke, M., Weyerts, H., Gross, M., Zander, E., Münte, T., \& Clahsen, H. (1997). How the brain processes complex words: an event-related potential study of German verb inflections. Cognitive Brain Research, 6, 37-52.

Perrin, F., Pernier, J., Bertrand, O., \& Echallier, J. F. (1989). Spherical splines for scalp potential and current density mapping. Electroencephalography and Clinical Neurophysiology, 72, 184-187.

Pinker, S. (1991). Rules of language. Science, 253, 153-195.

Pinker, S., \& Ullman, M. T. (2002). The past and future of the past tense. Trends in Cognitive Sciences, 6, 456-463.

Rodríguez-Fornells, A., Clahsen, H., Lleó, C., Zaake, W., \& Münte, T. (2001). Event-related brain responses to morphological violations in Catalan. Cognitive Brain Research, 11, 47-58.

Roehm, D., Bornkessel, I., Haider, H., \& Schlesewsky, M. (2005). When case meets agreement: event-related potential effects for morphology-based conflict resolution in human language comprehension. NeuroReport, 16, 875-878.

Rossi, S., Gugler, M. F., Hahne, A., \& Friederici, A. D. (2005). When word category information encounters morphosyntax: an ERP study. Neuroscience Letters, $384,228-233$.

Schreuder, R., \& Baayen, R. H. (1995). Modeling morphological processing. In L. Feldman (Ed.), Morphological aspects of language processing (pp. 131-154). Hillsdale, N.J: Lawrence Erlbaum.

Service, E., Helenius, P., Maury, S., \& Salmelin, R. (2007). Localization of syntactic and semantic brain responses using magnetoencephalography. Journal of Cognitive Neuroscience, 19, 1193-1205.

Soveri, A., Lehtonen, M., \& Laine, M. J. (2007). Word frequency and morphological processing in Finnish revisited. Mental Lexicon, 2, 359-385.

Steinhauer, K., \& Ullman, M. D. (2002). Consecutive ERP effects of morpho-phonology and morpho-syntax. Brain and Language, 83, 62-65.

Stockall, L., \& Marantz, A. (2006). A single route, full decomposition model of morphological complexity: MEG evidence. The Mental Lexicon, 1, 85-123.

Tanner, D., \& Van Hell, J. G. (2014). ERPs reveal individual differences in morphosyntactic processing. Neuropsychologia, 56, $289-301$.

Taulu, S., \& Simola, J. (2006). Spatiotemporal signal space separation method for rejecting nearby interference in MEG measurements. Physics in Medicine and Biology, 51, 1759-1768.

Tremblay, T., Monetta, L., \& Joanette, Y. (2009). Complexity and hemispheric abilities: evidence for a differential impact on semantics and phonology. Brain and Language, $108,67-72$.

Tyler, L. K., Marslen-Wilson, W. D., Randall, B., Wright, P., Devereux, B. J., Zhuang, J., et al. (2011). Left inferior frontal cortex and syntax: function, structure and behaviour in patients with left hemisphere damage. Brain, 134, 415-431.

Tyler, L. K., Stamatakis, E. A., Post, B., Randall, B., \& Marslen-Wilson, W. (2005). Temporal and frontal systems in speech comprehension: an flMRI study of past tense processing. Neuropsychologia, 43, 1963-1974.

Uusvuori, J., Parviainen, T., Inkinen, M., \& Salmelin, R. (2008). Spatiotemporal interaction between sound form and meaning during spoken word perception. Cerebral Cortex, 18, 456-466.

Vannest, J., Polk, T. A., \& Lewis, R. L. (2005). Dual-route processing of complex words: new fMRI evidence from derivational suffixation. Cognitive, Affective \& Behavioral Neuroscience, 5, 67-76.

Vartiainen, J., Aggujaro, S., Lehtonen, M., Hultén, A., Laine, M., \& Salmelin, R. (2009a). Neural dynamics of reading morphologically complex words. Neurolmage, $47,2064-2072$.

Vartiainen, J., Parviainen, T., \& Salmelin, R. (2009). Spatiotemporal convergence of semantic processing in reading and speech perception. Journal of Neuroscience, 29, 9271-9280.

Weyerts, H., Penke, M., Dohrn, U., Clahsen, H., \& Münte, T. F. (1997). Brain potentials indicate differences between regular and irregular German plurals. NeuroReport, 8, 957-962. 